\title{
SELF-INJURY IN ADOLESCENTS: A FIVE-YEAR STUDY OF CHARACTERISTICS AND TRENDS
}

\author{
Marina Bježančević ${ }^{1}$, Ivana Groznica Hržić ${ }^{1}$ \& Katarina Dodig-Ćurković ${ }^{1,2,3}$ \\ ${ }^{1}$ Unit of Child and Adolescent Psychiatry, University Hospital Center Osijek, Osijek, Croatia \\ ${ }^{2}$ Department of Psychiatry, Faculty of Medicine, Josip Juraj Strossmayer University of Osijek, Osijek, Croatia \\ ${ }^{3}$ Faculty of Dental Medicine and Health Osijek, Josip Juraj Strossmayer University of Osijek, Osijek, Croatia
}

received: 5.2.2018;

revised: 14.6.2018;

accepted: 3.8 .2018

\section{SUMMARY}

Background: Adolescent non-suicidal self-injurious behavior (NSSI) is a major public health concern. Although widespread, it is yet often a hidden problem. The purpose of this study was to explore the characteristics of self-injurious behavior in youth treated in an in-patient psychiatric unit.

Subjects and methods: The study included 105 adolescents with a history of NSSI (mean age 15 years, 80\% females) that underwent inpatient psychiatric treatment at a specialized facility. The factors assessed were sociodemographic data, frequency and type of NSSI, history of psychiatric disorder in family, existence of past traumatic event, alcohol, cigarettes and drug dependance and clinical psychiatric diagnosis. Retrospective-chart review study.

Results: Of all assessed, patients with NSSI were predominantly female adolescents. Mean age onset of NSSI in the sample was 15 years. Equal number of patients showed occasional and repetitive NSSI, using self-cutting as a most common mean of self-injury. Approximately $1 / 4$ of adolescents met criteria for an adjustment disorder and $1 / 4$ for a mixed disorder of conduct and emotions. A low $7.8 \%$ met the criterion for borderline personality disorder. We found a statistically significant correlation between alcohol consumption and frequency of self-injurious behavior.

Conclusions: Our study points to the fact that there has been an increase in prevalence of NSSI. Also, NSSI showed to be associated with female gender, alcohol consumption and a broad spectrum of comorbidities. Future research should focus not only on adolescents being hospitalized and treated, but should be representative of the whole young population because there are no national statistics on NSSI among young people in Croatia. Furthermore, future studies should focus on the origin of NSSI as opposed to its characteristics, in order for professionals to be able to prevent the issue.

Key words: adolescent - mental disorders - non-suicidal self injury

Abbreviations: NSSI-non-suicidal self-injury; $\quad$ BPD-borderline personality disorder; $\quad$ D-SIB - deliberate self-injurious behavior

$* * * * *$

\section{INTRODUCTION}

Different definitions are used to describe self-injurious behavior, among them terms like "parasuicide", "self-mutilation", "deliberate self harm", "deliberate self-injurious behavior". That heterogeneity in the terminology and definitions of self-injurious behavior is reflected in the diversity of instruments used to assess the phenomenon, making it difficult to compare the results of different studies. Term non-suicidal self-injury (NSSI) seems to have the clearest definition. It has been defined by the International Society for the Study of Self-injury as the deliberate, self-inflicted destruction of body tissue without suicidal intent and for purposes not socially sanctioned (2007). Furthermore, it is adopted as a new diagnostic entity in the 5th edition of the Diagnostic and Statistical Manual of Mental Disorders (DSM-5, American Psychiatric Association, 2013), Section III in the chapter "Conditions for Further Study". The DSM-5 criteria define NSSI as repetitive (occurring on more than 5 days within 1 year), direct altering body tissue in a non-socially sanctioned manner, and as being undertaken without suicidal intent. Although NSSI and attempted suicide are distinct behaviors differing in intent, form, and function, the behaviors co-occur at a high rate in adolescents: among both clinical (14-70\%) and nonclinical samples (3.8-7\%) (Andover et al. 2012). NSSI is a significant predictor of subsequent NSSI and subsequent suicide attempts (Wilkinson et al. 2011, Ferreira Bruco et al. 2018).

Non-suicidal self-injurious behavior is a major public health concern. It is most common among adolescents and young adults, and the age of onset is reported to occur between 12 and 15 years (systematic review by Cipriano et al. 2017). Although most prevalence studies of NSSI stem from the US, in last few years more epidemiological research originate from Europe. A relatively recent European comparison study of deliberate self injury by Brunner et al. (2014) included 11 European countries. They used the term deliberate self-injurious behavior (D-SIB) to describe any self-directed harmful behavior regardless of their suicidal intent, including NSSI. Overall lifetime prevalence of D-SIB was found to be $27.6 \% ; 19.7 \%$ reported occasional DSIB and $7.8 \%$ repetitive D-SIB. Lifetime prevalence ranged from $17.1 \%$ to $38.6 \%$ across countries. Estonia, 
France, Germany, and Israel had the highest lifetime rates of D-SIB, while students from Hungary, Ireland, and Italy reported low rates. In Croatia, there are no national statistics on NSSI among young people. Available data on suicide rates show that in last few years there has been an increase in rates in adolescents aged 15-19 years. In 2011 the rate was 3.5, and in 2015 the rate was 5.0/100.000 (Croatian Committed Suicide Registry).

The most common method is self-cutting (over 70\%) followed by head banging, scratching, hitting and burning; however, most individuals who engage in NSSI employ more than one method acting on the arms, legs, wrists and stomach (systematic review by Cipriano et al. 2017).

Fox et al. (2015) identified prior history of NSSI, hopelessness, Cluster B symptoms, female gender, depression, prior suicidal thoughts/behavior, exposure to peer NSSI, eating disorder and abuse as the strongest risk factors. Bentley et al. (2015) meta-analyzed studies examining the association between NSSI and internalizing pathology - all observed emotional disorders had an increased odds ratio for NSSI, except for bipolar disorder and social anxiety disorder. The association was the strongest with panic and post-traumatic stress disorder. Meszaros et al. (2017) by conducting a systematic literature review found a strong association between self-injurious behavior and externalizing pathology and disorders (attention deficit hyperactivity disorder, conduct disorder, antisocial personality disorder, oppositional defiant disorder, intermittent explosive disorder). Idig-Camuroglu and Gölge (2018) underlined childhood abuse as an important predictor of NSSI behavior.

Comorbidity with borderline personality disorder (Merza et al. 2017) and eating disorders is often reported (Cipriano 2017). Although listed as a diagnostic criterion for BPD (DSM- 5), NSSI may also occur in individuals who aren't diagnosed with BPD, and not every individual with BPD engages in self-injury (InAlbon et al. 2013). Differences between NSSI group and BPD group could suggest the need for defining NSSI as syndrome in its own right (Selby et al. 2012, Turner et al. 2015). Ferrara and colleagues (Ferrara et al. 2012) reported a positive correlation between depression scores and number of types of NSSI. Similarly, NSSI has shown to be a strong predictor of suicide attempt in clinical samples of adolescents with depression (Asarnow et al. 2011, Wilkinson et al. 2011, Tripković et. al 2014). There is growing evidence of altered pain perception in people engaging in NSSI (Bunderla \& Kumperščak 2015).

The four-factor model (Bentley et al. 2014) classifies NSSI regarding to its functionalities. This model describes intrapersonal and interpersonal processes, which can both be positively and negatively reinforcing the behavior. In the line of automatic negative reinforcement, NSSI serves the function of diminishing negative feelings or thoughts, while automatic positive rein- forcement describes the experience of pleasant or positive feelings or thoughts during or after engaging in NSSI. Social positive reinforcement describes reinforcing social interaction (i.e., getting attention or sending a message to others), while social negative reinforcement describes NSSI as a means to escape unpleasant social interactions. Most studies have found automatic negative reinforcement to be the most common function when endorsing in NSSI (Groschwitz et al. 2015, Bentley et al. 2014).

The aim of this study was to examine the characteristics of non-suicidal self-injurious behavior and associated factors in a sample of adolescents who selfinjure and were in-treated. In examining these factors, specific attention was given to history of psychiatric disorder in family, existence of past traumatic event, and alcohol, cigarettes and drug dependance and its association with NSSI.

\section{SUBJECTS AND METHODS}

\section{Organization of the study}

The research was conducted retrospectively.

\section{Subjects}

The study included 105 patients between the ages of 11 and 19 being hospitalized due to self-injurious behavior at the Department of Child and Adolescent Psychiatry, University Hospital Center Osijek during the period from 1 January 2010 to 31 December 2015.

We obtained consent of the head of Unit for Psychological Medicine, Unit of Child and Adolescent Psychiatry and Ethics Committee for Research at the Faculty of Medicine Osijek. Recorded data do not reveal the identity of the individual patient, and are presented collectively after statistical processing.

\section{Methods}

Medical records were analyzed from the history of the disease and the letters of release. From the retrospectively retrieved data the following variables were separated: age, gender, type of self-injury, frequency of self-injury attempts, age when self-injury started, comorbid diagnosis, family structure, previous existence of psychic disorders in the family, socioeconomic relations in the family, a school that adolescent attends, success at school, existence of traumatic events back to a year before the self-injury, consuming cigarettes, drugs, alcohol.

\section{Statistical Analysis}

The categorical data were represented by absolute and relative frequencies as they were numerically described by the arithmetic mean and the standard deviation. The differences of category variables were tested by $\chi^{2}$ test and, if needed, by Fisher's exact test. The normality of the distribution of numeric variables 
was tested by the Kolmogorov-Smirnov test. The differences between the normal distribution of numeric variables between the two independent groups were tested by the Student $t$ test, and in the case of a deviation from the normal distribution by the MannWhitney's U Test. All $\mathrm{P}$ values are two-sided. The level of significance was set at a risk level of $5 \%$ $(\mathrm{p}<0.05)$, and the computer program $\mathrm{R}$ (version 3.3.1, $\mathrm{R}$ Core Team, Vienna, Austria) was used for statistical analysis.

\section{RESULTS}

Participants were between 11 and 19 years old, with an average age of 15 (Figure 1).

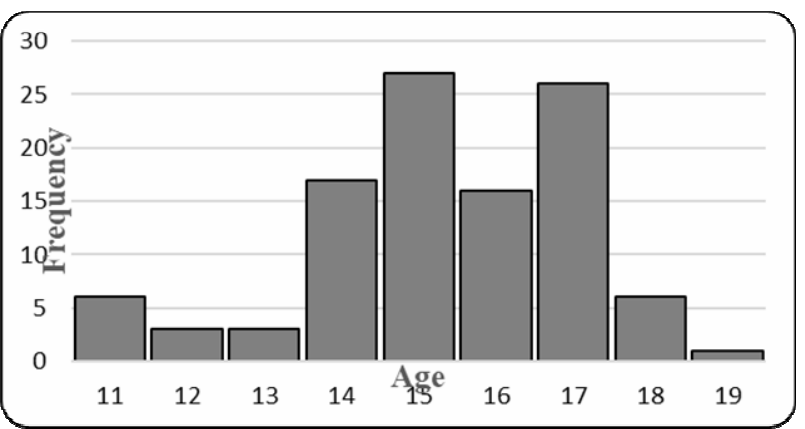

Figure 1. Histogram of patient age

Of the 105 patients in total, $84(80 \%)$ were females and $21(20 \%)$ males.

The frequency of self-injurious behavior was divided into two groups, more than five and less than five. 50 patients were in the first $(>5)$ and 55 in the other $(<5)$ group. We found no significant difference $\left(\chi^{2}\right.$ test, $\mathrm{p}=1.000$ ), nor when compared to gender.

Number of hospitalizations showed a growing trend, with a peak in the last year of conducting the study (Figure 2). The highest number of hospitalizations was 9 and only in one patient. Most often, there was one $(45.7 \%)$ or two $(26.7 \%)$ hospitalization. There were no found difference between the time spent on the Department and the frequency of self-injury (M-W test, $\mathrm{p}=0.832$ ).

Most common types of self-injuries are listed in Table 1.

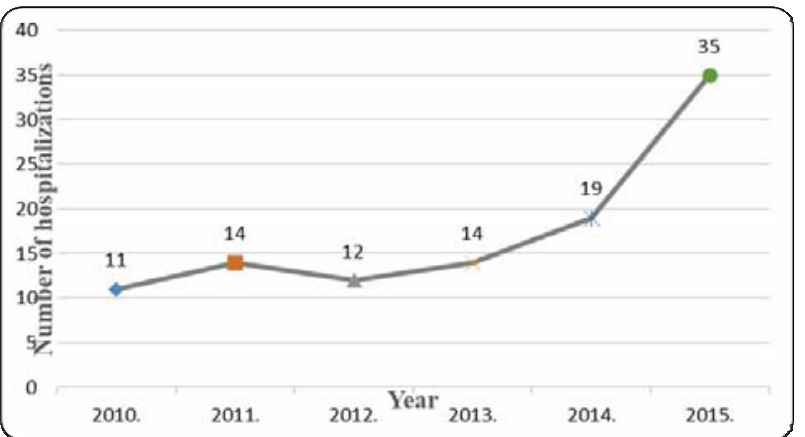

Figure 2. Number of hospitalizations in the observed period
Figure 3 shows types of sharp objects used in selfcutting, as the most common self-injury method.

The most common family community was a nuclear family (38.1\%). Mothers as single parents accounted for $21.9 \%$, and fathers for $8.6 \%$. Families with mother and stepfather accounted for $8.6 \%$, and with father and stepmother for $1.0 \%$. Patients who did not live with their parents were accommodated in: homes for children and youth upbringing $(6.7 \%)$, children homes $(3.8 \%)$, SOS villages $(5.7 \%)$, foster families $(1 \%)$ and youth communities $(1 \%)$.

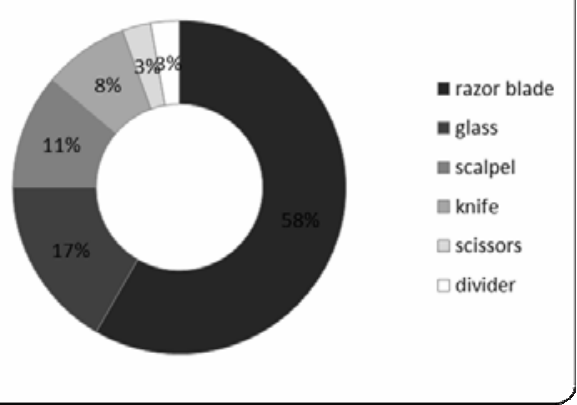

Figure 3. Types of sharp objects in self-cutting

Table 1. Type of self-injury and its frequency $(\mathrm{N}=105)$

\begin{tabular}{lcc}
\hline Type of self-injury & $\begin{array}{c}\text { Absolute } \\
\text { number }\end{array}$ & $\begin{array}{c}\text { Percentage } \\
(\%)\end{array}$ \\
\hline Self-cutting & 91 & 86.7 \\
Scratching & 6 & 5.6 \\
Causing burns & 4 & 3.8 \\
Hitting body on a subject & 3 & 2.9 \\
Stabbing items in the body & 1 & 1.0 \\
In total & 105 & 100 \\
\hline
\end{tabular}

Socioeconomic status was established only in those patients living in a mixed or a nuclear family. Out of 81 families, $13.6 \%$ were in a poor financial situation. The other $86.4 \%$ families were in a neat (both parents working) or a satisfactory (one parent working) socioeconomic position. No difference in the frequency of self-harming was observed, linked to socioeconomic conditions ( $\chi^{2}$ test, $\mathrm{p}=0.688$ ).

For 93 adolescents data on school success was available. Of the other 12, 6 were excluded from school and for 6 were no records. Most of the students had a good success (34.4\%). Very good success accounted 30.1\%, sufficient $23.7 \%$ and excellent $11.8 \%$. Mann-Whitney test showed no statistically significant difference between the number of self-injury episodes and school success $(p=0.072)$. Primary school students accounted $34.3 \%$.

The drug dependance was found in $18.1 \%$ of adolescents, alcohol in $36.2 \%$, and cigarettes in $41 \%$. There was a statistically significant difference between alcohol consumption and self-harming frequency $\left(\chi^{2}\right.$ test, $\mathrm{p}=0.038$ ). 
In 72 of cases we found a history of psychiatric disorder in family. Table 2 shows the results. Analysis revealed that self-harming did not occur more often in those families $\left(\chi^{2}\right.$ test, $\left.\mathrm{p}=0.394\right)$ (Table 2$)$.

Table 2. Types and frequency of psychiatric disorders in the family $(\mathrm{N}=72)$

\begin{tabular}{lcc}
\hline Psychiatric disorder & $\begin{array}{c}\text { Absolute } \\
\text { number }\end{array}$ & $\begin{array}{c}\text { Percentage } \\
(\%)\end{array}$ \\
\hline Suicide & 22 & 30.6 \\
Alcohol dependence & 20 & 27.8 \\
Posttraumatic stress disorder & 14 & 19.3 \\
Depression & 8 & 11.1 \\
Psychosis & 4 & 5.6 \\
Antisocial personality disorder & 4 & 5.6 \\
In total & 72 & 100 \\
\hline
\end{tabular}

Table 3. Type and share of traumatic events $(\mathrm{N}=62)$

\begin{tabular}{lcc}
\hline Traumatic event & $\begin{array}{c}\text { Absolute } \\
\text { number }\end{array}$ & $\begin{array}{c}\text { Percentage } \\
(\%)\end{array}$ \\
\hline End of a dating relationship & 14 & 22.6 \\
Moving & 10 & 16.1 \\
Sexual abuse & 10 & 16.1 \\
Death of a close person & 10 & 16.1 \\
Parents divorce & 8 & 12.9 \\
Miscarriage & 3 & 4.8 \\
Peer violence & 3 & 4.8 \\
Disease in family & 2 & 3.2 \\
Rape & 2 & 3.2 \\
In total & 62 & 100 \\
\hline
\end{tabular}

Table 4. The proportion of comorbid psychiatric diagnoses

\begin{tabular}{lcc}
\hline Mental disorder & $\begin{array}{c}\text { Absolute } \\
\text { number }\end{array}$ & $\begin{array}{c}\text { Percentage } \\
(\%)\end{array}$ \\
\hline F1 - Substance use disorders & 4 & 1.9 \\
F23 - Acute and transient & 7 & 3.4 \\
$\quad$ psychotic disorders & & \\
F3 - Affective disorders & 21 & 10.2 \\
F41 - Anxiety disorders & 13 & 6.3 \\
F43 - Adjustment disorders & 50 & 24.4 \\
F44 - Disociative (conversion) & 2 & 1.0 \\
$\quad$ disorder & & \\
F45 - Somatoform disorder & 2 & 1.0 \\
F5 - Eating disorders & 6 & 2.9 \\
F60 - Personality disorders & 16 & 7.8 \\
F70 - Mild mental retardation & 3 & 1.5 \\
F90 - Hyperkinetic disorder & 3 & 1.5 \\
F91 - Conduct disorders & 26 & 12.7 \\
F92 - Mixed disorders of & 48 & 23.4 \\
$\quad$ conduct and emotions & & \\
F93 - Emotional disorders with & 4 & 1.9 \\
$\quad$ onset specific to childhood & & \\
\hline
\end{tabular}

Traumatic events with a great influence on mental health have occurred in 62 adolescents. Table 3 reveals their extent and share. The difference between the frequency of self-harming in patients who experienced traumatic events and those who did not, did not exist $\left(\chi^{2}\right.$ test, $\mathrm{p}=0.316$ ).

Table 4 lists the most common mental disorders diagnosed in the selected sample of adolescents.

\section{DISCUSSION}

\section{Age}

Average age of adolescents who self-injured in our observed group was 15 years. Occasional and repetitive self-injurious behavior were equally represented. Compared to European comparison study by Brunner et al. (2014), mean age of self-injury is consistent: their results showed mean age of 14.9 for occasional D-SIB and 15 for repetitive D-SIB. Ratio of occasional and repetitive self-injury differs, as they reported higher prevalence of occasional D-SIB (19.73\%) and lower of repetitive D-SIB (7.83\%). Other studies also showed higher prevalence of occasional self-injurious behavior compared to the repetitive form (Zetterqvist et al. 2013, Plener et al. 2012). A systematic review (20052011) by Muehlenkamp et al. (2012) of empirical studies reporting on the international prevalence of NSSI and D-SIB concluded that both hade a comparable prevalence and no statistically significant differences were found between.

\section{Gender differences}

Female gender is significantly associated with higher rates of NSSI (meta-analysis by Bresin and Schoenleber 2015). The ratio was confirmed in our study - in our inpatient population females were four times more prevalent. The reasons for these gender differences are not yet clear. Some authors argue (Cerutti et al. 2011, Sarno et al. 2010) that females are more likely to disclose their NSSI than males, and therefore to be captured by statistics. Gandhi et al. (2017) highlighted the fact that gender differences observed in NSSI are also observed in depression and anxiety. They explained the thesis by increasing evidence suggesting that in females estrogen and progesterone may modulate mood through their influence on GABA, 5-HT and/or dopamine systems and influence on NSSI behavior.

\section{Number of hospitalizations}

We observed progressive growth trend of hospitalization of patients with diagnosis of self-injury. In comparision to year 2014, in the last year of conducting the study (2015) the number nearly doubled. But, we observed a progressive growth trend of hospitalizations at our department in general, which makes difficult to diferentiate the cause of this growth.

\section{Type of self-injury}

In our group of interest $87 \%$ of adolescents injured themselves in form of cutting. Less used types of self- 
injury were scratching, causing burns, hitting body on a subject and stabbing items in the body. The result matches world trends, as cutting oneself with a sharp object is a main mean of self-injury (in over $70 \%$ adolescents - systematic review by Cipriano et al. 2017).

\section{Family structure}

The family is the most powerful protective factor for all forms of psychiatric disorders in childhood and adolescence. So, low quality of relationships within the family and reduced parental involvement are important concomitant of self-harm (Brunner et al., 2014). In our research only $1 / 3$ of families were nuclear, $1 / 3$ families were with mothers or fathers as single parents, and the rest were children excluded from family and accommodated in foster families, children homes or youth communities. The high number of families that weren't nuclear could indicate that family discord serves as a risk factor for NSSI.

\section{Socioeconomic status}

A population-based cohort study in Stockholm $(\mathrm{N}=165,923)$ by Lodebo et al. (2017) showed an association between parental socioeconomic position (defined by parental education and household income) and self-harm: adolescents from the lower income categories were 1.08 to 1.19 times more likely to selfharm. In our observed group we did not found any strong correlates between parental unemployment and poor financial situation with prevalence of NSSI. Most of families $(86 \%)$ were in a neat or a satisfactory financial state.

\section{School success}

Poor academic functioning and inconsistent school attendance are early signs of emerging or existing mental health problems during childhood and adolescence (literature review by DeSocio and Hootman, 2004). In our observed group 6 out of 105 adolescents were excluded from school and for 6 there were no records. Most of the students (34\%) had a good success, and very good success accounted for high $30 \%$. There was no statistically significant difference found between the number of self-injury episodes and school success or school attendance.

\section{Smoking, alcohol consumption and use of psychoactive substances}

Adolescents who engage in NSSI were more likely to present several health-risk behaviors, such as substance abuse, risky sexual behaviors, and maladaptive eating habits (Giletta et al. 2012). Furthermore, girls who engage in alcohol and substance abuse seem to be at higher risk of D-SIB compared with their male peers (Brunner et al 2014). The cigarettes dependence was found in $41 \%$ of adolescents, alcohol in $36 \%$, and drugs in $18 \%$. There was a statistically significant difference between alcohol consumption and self-harming frequency. Mechanisms responsible for alcohols ability to increase the risk for self-injurious behavior include alcohols ability to increase psychological distress, increase aggressiveness, propel suicidal ideation into action through suicide-specific alcohol expectancies and constrict cognition which impairs the generation and implementation of alternative coping strategies (Hufford 2001).

\section{Influence of hereditary factors (psychiatric disorder in the family)}

Parental psychiatric disorders are associated with an increased risk of self-destructive behavior in children. Kopp and Beauchaine (2007) suggested that children with maternal depression and paternal patterns of antisocial personality disorder are at especially high risk for psychopathology, both of internalizing and externalizing natures. Self-harm seems to be strongly associated with a family history of self-harm, physical ill-treatment and sexual abuse (Rijsselberge et al 2009). In 72 adolescent there was a psychiatric disorder present in the family. Almost two thirds referred to suicide and alcohol dependence (31\% and 28\%). But, results showed no statistical significance between those variables.

\section{The impact of traumatic experiences}

Childhood abuse has been associated with increases in NSSI behaviors in adolescents (a systematic review by Serafini et al. 2017). Exposure to any adverse childhood experience occuring within the first 16 years of life, regardless of the type and event, is significantly associated with NSSI (Wan et al. 2015, Duke et al. 2010). But, some recent research provide differentiated findings on the experience of adverse childhood events. In a study by Thomassin et al. 2016, only child emotional abuse remained significantly associated with NSSI, when different types of adverse childhood experiences were analyzed simultaneously. This is in line with a review and a meta-analysis (Klonsky and Moyer 2008, Maniglio 2011), finding the experience of sexual abuse to be only moderately linked to the development of NSSe. In our sample traumatic events have occurred in 62 of 105 adolescents. End of a dating relationship was traumatic in $23 \%$ and moving, sexual abuse, death of a close person each in $16 \%$ of adolescents. Less represented traumatic experiences were parents' divorce, miscarriage, peer violence, disease in family.

\section{Co-morbid psychiatric disorders}

Overall, the largest diagnostic groups with cooccurring NSSI were, in descending order: Adjustment disorders (F43), Mixed disorders of conduct and emotions (F92), Conduct disorders (F91), Affective disorders (F3-) and Borderline personality disorder (F60.3). These results partially overlap with a similar in-patient adolescent study by Sevecke et al. (2017, n=130): they 
found NSSI clusters for diagnostic groups of affective disorders, substance use disorders and borderline personality disorder. Association between depression and NSSI is well studied and reported in many researches (comparative European study by Brunner et al. 2014, Nock et al. 2006). In our study the borderline personality disorder had an unexpected low share $(7.8 \%)$ compared to studies which have shown BPD in 20$75 \%$ of adolescents engaging in NSSI (Andrewes et al. 2017, In-Albon et al. 2013, Nock et al. 2006). Comorbid eating disorder was found in only $2.6 \%$ of adolescents which is in line with previous findings (Sevecke et al. 2017, Ruuska et al. 2005).

\section{Limitations}

Our study was based on retrospectively retrieved data from medical histories, and this data were not gathered using standardized diagnostic instruments. The diagnoses represent a source of potential bias. Also, a retrospective study limited the analysis on data that were documented, with no option of extending our research to some other characteristics of NSSI of our interest.

\section{CONCLUSIONS}

Our research observed some basic sociodemographic and clinical characteristics of NSSI. Of all assessed, patients with NSSI were predominantly female adolescents. Mean age onset of NSSI was 15 years. Self-cutting with a sharp object was the most common mean of self-injury. A strong association was found between alcohol consumption and frequency of self-harm. Our study points to the fact that there has been an increase in prevalence of NSSI. Also, NSSI is associated with a broad spectrum of comorbidities. Adolescents presenting NSSI behavior are not a homogenous group and all should be considered at high risk of suicide that requires careful evaluation and management. Thus, especially programs for suicide prevention should be implemented. Future research should focus not only on adolescents being hospitalized and treated, but should be representative of the whole young population in Croatia. There are no national statistics on NSSI among young people in Croatia so the extent of this behavior is unknown. Furthermore, future studies should focus on the origin of NSSI as opposed to its characteristics, in order for professionals to be able to prevent the issue. There is also a lack of cross-country studies to learn differences across cultures, as a lack of standardized terminology and measurement for self-injurious behavior making the result of studies difficult to compare.

\section{Acknowledgements: None.}

\section{Conflict of interest: None to declare.}

\section{Contribution of individual authors:}

Marina Bježančević - conception of the study, acquisition of the data, drafting of the manuscript.

Ivana Groznica Hržić - acquisition and analysis of the data, drafting of the manuscript.

Katarina Dodig-Ćurković - conception of the study, final approval.

\section{References}

1. American Psychiatric Association: Diagnostic and Statistical Manual of Mental Disorders 5th edition (DSM 5). Washington: American Psychiatric Association, 2013

2. Andover MS, Morris BW, Wren A, Bruzzese ME: The cooccurrence of non-suicidal self-injury and attempted suicide among adolescents: distinguishing risk factors and psychosocial correlates. Child Adolesc Psychiatry Ment Health 2012; 6:11

3. Asarnow JR, Porta G, Spirito A, Emslie G, Clarke G, Wagner KD, Vitello B, Keller M, Birmaher B, McCraken $J$, Mayes T, Berk M, Brent DA: Suicide attempts and nonsuicidal self-injury in the treatment of resistant depression in adolescents: Findings from the TORDIA study. J Am Acad Child Psy 2011; 50:772-781

4. Bentley $\mathrm{KH}$, Cassiello-Robbins CF, Vittorio L, SauerZavala S, Barlow DH: The association between nonsuicidal self-injury and the emotional disorders: A meta-analytic review. Clin Psychol Rev 2015; 37:72-88

5. Bentley K, Nock MK, Barlow DH: The four function model of nonsuicidal self-injury. Clinical Psychological Science 2014; 2:638-56

6. Bhugra D, Singh J, Fellow-Smith E, Bayliss C: Deliberate self-harm in adolescents. A case study among two ethnic groups. Eur J Psych 2002; 16:145-151

7. Boxer P: Variations in risk and treatment factors among adolescents engaging in different types of deliberate selfharm in an inpatient sample. J Clin Child Adoles Psychol 2010; 39:470-480

8. Brunner R, Kaess M, Parzer P, Fischer G, Resch F, Carli $V$, Hoven C, Wasserman C, Sarchiapone M, Wasserman D: Characteristics of non-suicidal self-injury and suicide attempts among adolescents in europe: results from the european research consortium seyle European Psychiatry, ISSN: 0924-9338, 2013; 28:1

9. Bunderla $T \&$ Kumperščak HG: Altered pain perception in self-injurious behavior and the association of psychological elements with pain perception measures: a systematic review. Psychiatr Danub 2015; 27:346-354

10. Croatian Committed Suicide Registry, Data source: WHO/Europe, HFA Database, July 2016 Data analysis: $\mathrm{HZJZ} / \mathrm{CIPH}$

11. Degmecic D\& Filaković P: Depression and suicidality in the adolescents in Osijek, Croatia. Coll Antropol 2008; 32:143

12. DeSocio J \& Hootman J: Children's Mental Health and School Success, J Sch Nurs 2004; 20:189-96

13. Duke NN, Pettingell SL, McMorris BJ, Borowsky IW: Adolescent violence perpetration: associations with multiple types of adverse childhood experiences. Pediatrics 2010; 125:e778-786 
14. Esposito-Smythers C, Goldstien T, Birmaher B, Goldstein $B$, Hunt J, Ryan N, Axelson D, Strober M, Gill MK, Hanley A, Keller M: Clinical and psychosocial correlates of non-suicidal self-injury within a sample of children and adolescents with bipolar disorder. J Affect Disorders 2010; 125:89-97

15. Ferreira Bruco ME, Gamlin C, Bradbury J, Bill S, Armour C, Agius M: Self harm and suicidality: an audit of follow-up in primary care. Psychiatr Danub 2018; 30(Suppl. 7):610-615

16. Gollust SE, Eisenberg D, Golberstein E: Prevalence and correlates of self-injury among university students. $\mathrm{J} \mathrm{Am}$ Coll Health 2008; 56:491-498

17. Heath NL, Toste JR, Nedecheva T, Charlebois A: An examination of nonsuicidal self-injury among college students. J Ment Health Counsel 2008; 30:137-156

18. Favazza AR: The coming of age of selfmutilation. J Nerv Ment Dis 1998; 186:259-268

19. Favazza AR, Simeon D: Self-mutilation. In E. Hollander, \& D. Stein (Eds.) Impulsivity and aggression ( $p p .185-$ 200). New York: Wiley, 1995

20. Fox KR, Franklin JC, Ribeiro JD, Kleiman EM, Bentley KH, Nock MK: Meta-analysis of risk factors for nonsuicidal self-injury. Clin Psychol Rev 2015; 42:156-67

21. Greydanus DE, Shek D: Deliberate self-harm and suicide in adolescents. Keio J Med 2009; 58:144-151

22. Groschwitz RC, Kaess M, Fischer G, Ameis N, Schulze UM, Brunner R, et al.: The association of non-suicidal self-injury and suicidal behavior according to DSM-5 in adolescent psychiatric inpatients. Psychiatry Res 2015, 228:454-461

23. Hawton K, Harriss L, Hodder K, Simkin S, Gunnell D: The influence of the economic and social environment on deliberete self-harm and suicide: an ecological and person-based study. Psychol Med 2001; 31:827-836

24. Hilt LM, Cha CB \& Nolen-Hoeksema S: Nonsuicidal selfinjury in young adolescent girls: Moderators of the distress-function relationship. Journal of Consulting and Clinical Psychology 2008; 76:63-71

25. Hufford MR: Alcohol and suicidal behavior. Clinical Psychology Review 2001; 12:797-811

26. Idig-Camuroglu $M$ \& Gölge ZB: Non-suicidal self-injury among university students in Turkey: the effect of gender and childhood abuse. Psychiatr Danub 2018; 30:410-420

27. International Society for the Study of Self-injury: Definitional issues surrounding our understanding of self-injury. Conference proceedings from the annual meeting, 2007

28. Jacobson CM \& Gould M: The epidemiology and phenomenology of non-suicidal self-injurious behavior among adolescents: a critical review of the literature. Arch Suicide Res 2007; 11:129-147

29. Joiner et al.: Main Predictions of the Interpersonal-Psychological Theory of Suicidal Behavior: Empirical Tests in Two Samples of Young Adults, J Abnorm Psychol 2009; 118:634-646

30. Kerr PL, Muehlenkamp JJ \& Turner JM: Non-suicidal self-injury: A review of current research for family medicine and primary care physicians. Journal of the American Board of Family Medicine 2010; 23:240-259

31. Kidger et al.: Adolescent self-harm and suicidal thoughts in the ALSPAC cohort: a self-report survey in England, BMC Psychiatry 2012; 12:69

32. Klonsky ED: Non-suicidal self-injury: an introduction. $J$ Clin Psychol 2007; 63:1039-1043
33. Klonsky ED \& Glenn CR: Assessing the functions of nonsuicidal self-injury: psychometric properties of the inventory of statements about self-injury (ISAS). J Psychopathol Behav Assess 2009; 31:215-219

34. Klonsky ED \& Moyer A: Childhood sexual abuse and nonsuicidal self-injury: meta-analysis. Br J Psychiatry 2008; 192:166-70

35. Kopp LM \& Beauchaine TP: Patterns of psychopathology in the families of children with conduct problems, depression and both psychiatric condition. J Abnorm Child Psychol 2007; 35:301-12

36. Leo de D \& Heller ST: Who are the kids who self harm? An Australian self-report school survey. The medical journal Australia. MJA 2004; 181:140-144

37. Lindsay GB \& Rainey J: Psychosocial and pharmacologic explanation of nicotine's "gateway drug" function. J Sch Health 1997; 67:123-126

38. Lodebo BT, Möller J, Larsson J, Engström K: Socioeconomic position and self-harm among adolescents: a population-based cohort study in Stockholm, Sweden, Child Adolesc Psychiatry Ment Health 2017; 11:46

39. Madge N, Hewitt A, Hawton K, de Wilde E, Corcoran P, Fekete S: Deliberate selfharm within an international community sample of young people: comparative findings from the Child \& Adolescent Self-harm in Europe (CASE) Study. J Child Psychol Psychiatry 2008; 49:667-77

40. Maniglio R: The role of child sexual abuse in the etiology of suicide and non-suicidal self-injury. Acta Psychiatr Scand 2011; 124:30-41

41. Merza K, Papp G, Molnár J, Kuritárné Szabó I: Characteristics and development of nonsuicidal super self-injury among borderline inpatients. Psychiatr Danub 2017; 29:480-489

42. National Youth Program 2009-2013, "Narodne novine" Croatia; Class: 552- 01/09-02/09;2009

43. Nixon MK, Cloutier P, Jansson SM: Nonsuicidal selfharm in youth: a population- based survey. CMAJ 2008; 178:306-312

44. Nock $M$ \& Favazza AR: Non-suicidal self-injury: definition and classification. American Psychological Association Washington DC, 2009

45. Nock MK, Joiner TE, Gordon KH, Lloyd-Richardson E, Prinstein MJ: Non-suicidal self-injury among adolescents: diagnostic correlates and relation to suicide attempts. Psychiatry Res 2006; 144:65-72

46. Nock $M K$ \& Prinstein MJ: A functional approach to the assessment of self-mutilative behavior. J Consult Clin Psychol 2004; 72:885-90

47. Plener PL, Schuhmacher T, Munz LM, Groschwitz RC: The longitudinal course of non-suicidal self-injury and deliberate self-harm: searching for predictors: a systematic review of the literature. Borderline Personal Disord Emot Dysregul 2015; 2:2

48. Putnam FW: The impact of trauma on child development. Juvenile and Family Court Journal, 2006

49. Rijsselberge Van L, Portzky G, Heeringen van C: Self harm in adolescents in Flanders. Dutch Journal of Psychiatry 2009; 51:629-640

50. Serafini G, Canepa G, Adavastro G, Nebbia J, Belvederi Murri M, Erbuto D, Pocai B, Fiorillo A, Pompili M, Flouri E, Amore M: The relationship between childhood maltreatment and non-suicidal self-injury: A systematic review. Front .Psychiatry 2017; 8:149 
51. Sevecke K, Bock A, Fenzel L, Gander M, Fuchs M: Nonsuicidal self-injury in a naturalistic sample of adolescents undergoing inpatient psychiatric treatment: prevalence, gender distribution and comorbidities. Psychiatr Danub 2017; 29:522-528

52. Simeon D \& Favazza AR: Self-injurious behaviors: Phenomenology and assessment. In D. Simeon, \& E. Hollander (Eds.), Self-injurious behaviors: Assessment and treatment (pp. 1-28). Washington, DC: American Psychiatric Publishing, 2001

53. Thomassin $K$, Shaffer A, Madden A, Londino DL: Specificity of childhood maltreatment and emotion deficit in nonsuicidal selfinjury in an inpatient sample of youth. Psychiatry Res 2016; 244:103-8

54. Tripković M, Sarajlić Vuković I, Frančišković T, Vuk Pisk S, Krnić S: Depression and auto-aggressiveness in adolescents in Zagreb. Psychiatr Danub 2014; 26(Suppl. 3): 422-427

55. Walsh B: Treating self-injury: a practical gude. Guilford press, 2006

56. Wan Y, Chen J, Sun Y, Fangbiao T: Impact of childhood abuse on the risk of non-suicial self-injury in mainland Chinese adolescents, PloS ONE 2015; 10:e0131239

57. Whitlock J: Self-injurious behavior in adolescents. PloS Medicine 2010; 7

58. Whitlock J, Eckenrode J, Silverman D: Selfinjurious behaviors in a college population. Pediatrics 2006; 117:1939-1948

59. Whitlock $J$ \& Knox KL: The relationship between self-injurious behavior and suicide in a young adult population. Arch Pediatr Adolesc Med 2007; 161:634-640

60. Wilkinson P, Kelvin R, Roberts C, Dubicka B, Goodyer I: Clinical and psychosocial predictors of suicide attempts and nonsuicidal self-injury in the Adolescent Depression Antidepressants and Psychotherapy Trial (ADAPT). Am J Psychiat 2011; 168:495-501

61. Yates TM: The developmental psychopathology of self-injurious behavior: Compensatory regulation in posttraumatic adaptation. Clinical Psychology Review 2004; 24:35-74

62. Young People and Self-Harm: A National Inquiry. What do we already know? prevalence, risk factors \& models of intervention, 2004

Correspondence:

Marina Bježančević, MD

Unit of Child and Adolescent Psychiatry, University Hospital Center Osijek

Josipa Huttlera 4, 31000 Osijek, Croatia

E-mail: marina.bjezancevic@gmail.com 